\title{
Students' activity in modern educational space: psychological and pedagogical aspects
}

\author{
Svetlana Aleksandrovna Vasyura ${ }^{11}$, Olga Valerievna Nikitina $^{1}$, Olga Vladimirovna \\ Solodiankina $^{2}$, Aleksandr Nikolaevich Averin ${ }^{2}$, and Marina Ivanovna Maletova ${ }^{3}$ \\ ${ }^{1}$ Udmurt State University, Department of General Psychology, Institute of Pedagogy, Psychology and \\ Social Technologies, Izhevsk, Russia \\ ${ }^{2}$ Udmurt State University, Department of Social Work, Institute of Social Communication, Izhevsk, \\ Russia \\ ${ }^{3}$ Udmurt State University, Department of Foreign Languages for Law, Economics and Management, \\ Institute of Language and Literature, Izhevsk, Russia
}

\begin{abstract}
Over the last decade, the issue of student activity in the educational space is of growing worldwide interest from the academic community and practitioners. With the rapid growth of information and communication technologies penetrating all areas of life, educational space particularly, the research on diverse types of student activity has attracted the attention of international scholars. Student activity transfers to virtual space, so learning and communication activities are largely transformed. Thus, the academic community finds it crucial to analyze integrated activity. The research aims to study integrated student activity in five areas of life and identify its links with the orientation of their communicative activity. It engaged 104 undergraduates from Udmurt University and Medical College. The research was based on Volochkov and Popov's method of "Diagnostics of student activity" and Vasyura's method of measuring the orientation of communicative activity. Methods of mathematical statistics were applied to process the data. In student educational activity, three components of activity composition are correlated with the orientation of communicative activity. It is identified that student as an actor of educational activity is likely to be satisfied with academic success and efforts to overcome study barriers if he or she is oriented to actively interact with other actors of educational space. The data may provide a ground for devising a counseling programme to manage the development of activity in various areas of life.
\end{abstract}

Keywords: student activity, interaction, learning, education, information and communication technologies

\section{Introduction}

The issue of student activity, its influence on effective learning and subjective well-being has lately been in the focal point of researchers. With intensive development of information

${ }^{1}$ Corresponding author: vasyura@inbox.ru 
and communication technologies capturing all life areas, notably educational space, student activity is seriously scrutinized by academics and practitioners [1]. The research based on psychological-pedagogical ground may be of crucial importance for educational institutions. The results of the research may lay a foundation for developing psychological and pedagogical counseling technologies to set up student counseling services to manage student activity in the educational space.

The problem of integrated student activity remains understudied although researchers attempt to study diverse areas of activity - educational, cognitive, volitional, communicative, social activities, etc. [2]. Learning activity is addressed from the perspective of self-regulated learning. These ideas have caused the growing interest of European researchers and encouraged them to develop diverse models for self-regulated learning [3]. The issues of academic procrastination were studied as part of the elimination of student learning activity [4].

Student educational engagement tends to be one of the representations of student educational activity in educational space [5]. According to York, Gibson, Rankin [6], engagement in learning is the basis for success in studies. The development of student own understanding of learning success is underpinned by the results of this learning [7]. The transition from external criteria to an internal assessment of own progress i.e., "sense of self-perception" (interest to disciplines, involvement in the educational process, etc.) may be singled out among major areas of learning success [8]. The activity of students is transferring to the virtual world [9], causing transformations in learning, cognition, and communications [10]. Psychologists tend to observe flexibility in student digital behaviour [11], willingness to forward and receive information, as well as to select contacts, etc. [12].

In lieu of growing research interest to student activity, the issue of conducting analysis of integrated activity in diverse academic and non-academic life areas is viewed as essential. Student life space involves five typical areas of interactions: learning activity, cognition, communication, contemplation, and reflection. In the research, student integrated activity was studied in these areas with the focus on the correlations with student communicative activity in real-life and virtual communications. The research engages 104 first-to-second year undergraduates at Udmurt University and Medical College in Izhevsk. The participants were aged 17-23 years old. The research was conducted on a volunteer-driven basis.

\section{Methods}

The research is based on empirical, mathematical and statistical methods. Method of "Diagnostics of student activity" (DAS 2) $[13,14]$ was used to assess student activity. This method represents instruments measuring multidirectional types of a human activity based on integrated theoretical and psychometric ground. It contains 93 indicators and tests student activity in such interaction areas as communication, contemplation, education, cognition, reflection. Integral coefficient of reliability (Cronbach's alpha) in all indicators of DAS 2 method comes to 0.84 .

Application of DAS 2 method is underpinned by the assumption that it would allow both identification of five areas of student activity and diagnostics of its three-component model-need in interactions, volitional control, satisfaction from interaction results - in each of these areas.

Vasyura's method of measuring the orientation of communicative activity in real-life and virtual communications was also applied in the research [15]. The method aimed to examine orientations of student communicative activity which involves communicative activity itself, informative, cognitive, emotive, conative, and creative activities. The method was verified by psychometric tests and has predictive value in assessing student activity in 
real-life and Internet communications. According to guidelines of the method, students ranked scales of activity four times, first they performed two series of ranking of "I-real" indicators relevant to their preferences in real-life and virtual communications, then they did two ranking series of "ideal" in real and virtual interactions. Each student was profiled according to their communicative activity based on ranking scales (communicative activity itself, emotive, informative, cognitive, emotive, conative, creative activities). Excel and SPSS 17.0 were used to process empirical data. The results were justified by descriptive statistics, Spearman correlation coefficient.

\section{$3 \quad$ Results}

Based on DAS 2 method, the data prove that reflections of student activity are individually unique. As a result of measuring orientation of student communicative activity, orientation-driven profile was identified in direct communication related to communicative activity itself and emotive activity, whereas virtual communication engaged informative and communicative activity. It is suggested to consider the data from the correlation analysis of indicators based on DAS 2 and measuring the orientation of communicative activity methods (table 1 ).

Table 1. Correlation of scales of activity in diverse areas and orientation of student communicative activity.

\begin{tabular}{|l|c|}
\hline \multicolumn{2}{|c|}{ Structural components of activity and orientation } \\
\hline Actor's choice
\end{tabular}

The table demonstrates only significant correlations.

Notably, the method of measuring communicative activity identified that with lower rank, any of the orientations is more expressed, and that implies all above-mentioned activities. As seen from the table, students with emotive orientation in virtual communication demonstrate correlations with actor's choice. The choice is correlated with creative orientation in virtual communications. Basically, actor's control in contemplation, learning and reflection is correlated with the orientation of communicative activity in real-life communication. In the component of "actor's satisfaction from interaction results" indicators like cognition, learning and reflection are linked to the orientation of communicative activity in virtual and real-life communications.

\section{Discussion}

Students tend to demonstrate their activity in direct communications that aims to establish interpersonal contacts, emotional and trustful interactions with other population groups. In 
virtual interactions, they are oriented to receive information and establish interpersonal contacts.

Once students demonstrate stronger needs in communication process, then emotive orientation in virtual interactions is more expressed. Thus, aspirations to interact and to select communication partners are related to willingness to establish emotional relations and satisfy need in friendship and trustful interactions in virtual world.

In contrast to strong needs in academic interactions, creative orientation is insignificantly expressed in student virtual communications, the converse is also true. The more self-regulation in student contemplation is expressed, the more prominently emotive orientation is viewed in direct communications.

Impulsive student reactions to academic failures may be related to high informative activity in direct communications. Alongside high reflection - organization of own time to execute self-reflection and find own place in the world - students demonstrate low communicative activity in direct interactions.

Whereas high volitional control and need in interaction are demonstrated in reflection, cognitive orientation is more expressed in direct communications. While satisfaction from interaction results is higher in cognition, higher communicative activity and lower informative orientations are seen in virtual communications. With the increase of actor's satisfaction from interaction results, an increase of conative activity can be observed in learning in real-life communications. Whereas an increase in interaction results is observed in reflection, conative orientation is decreased in direct communications, the converse is also true.

Remarkably, reflection as a meaning-making activity in components of "actor's control" and "actor's satisfaction from interaction results" is correlated with communicative and cognitive activities, the correlation with conative orientation is also observed in direct communications. Thus, students ponder on their being, identify interpersonal contacts, get acquainted with communication partners, determine co-actions with counterparts.

A three-component model of activity (need in interaction, volitional control, satisfaction from interaction results) correlates with communicative activity in learning and can be of research interest. Consequently, the creative orientation of undergraduates in virtual communication and informative activity in direct communication can be viewed as anti-predictors of actor's choice and actor's control in the learning activity. Likewise, conative orientation as a desire to manage participants' behavior in direct communication and regulate co-actions relates to satisfaction from learning activity. Evidently, student as an actor of educational activity will be encouraged not only by success in learning, he or she will also be satisfied with efforts against barriers in learning, providing that he or she is oriented to interact with other students, advisors, teachers, etc.

The data may lay a foundation for designing psychological and pedagogical counseling programmes to help the development of student activity in different areas of life and prevent students from disinterest in studies and from Internet-addiction. Student counseling service implies integrating efforts of all actors in the educational space and involves individual and group work.

\section{Conclusion}

Student life in the modern world is organized as a system of situations, diverse activities, and forms of interactions that embraces communication, contemplation, educational activity, cognition, and reflection.

The research results stated that:

- correlations between different areas of student activity are numerous and multifaceted; 
- out of all areas of student interactions, learning activity is primarily correlated with student communicative activity in real and virtual communications.

The research results may be extrapolated in education and used by teachers, educators, psychologists, counsellors; those who confront problems of student activity in educational process and other areas of life.

\section{References}

1. U.S. Zakharova, K.A. Vilkova, J. Mod. Foreign Psy. 9(3), 87-96 (2020). https://doi.org/10.17759/jmfp.2020090308

2. K.S. Shalaginova, E.V. Dekina, Psy.-Edu. Stud., 12(3), 80-94 (2020). https://doi.org/10.17759/psyedu.2020120305

3. M. Boekaerts, P.R. Pintrich, M. Zeidner, Handbook of self-regulation: Theory, research and applications (Academic Press, San Diego, C.A, 2000)

4. I.N. Kormachova, Psy. Edu. 3(1), 61-70 (2021). https://doi.org/10.33910/2686-9527-2021-3-1-61-70

5. D.A. Kasatkina, A.M. Kravchenko, R.B. Kupriyanov, E.V. Nekhorosheva, J. Mod. Foreign Psy. 9(3), 59-68 (2020). https://doi.org/10.17759/jmfp.2020090305

6. T.T. York, C. Gibson, S. Rankin, Prac. Asses., Res., and Eval. 20(5), 1-20 (2015). https://doi.org/10.7275/hz5x-tx03

7. V.N. Shlyapnikov, Psy. Sci. and Edu. 26(1), 66-75 (2021). https://doi.org/10.17759/pse.2021260104

8. S.V. Yaroshevskaya, T.A. Sysoeva, Psy. Sci. and Edu. 26(1), 92-101 (2021). https://doi.org/10.17759/pse.2021260106

9. V.N. Panferov, et al., Soc. Psy. and Soc. 11(1), 127-143 (2020). https://doi.org/10.17759/sps.2020110108

10. R.M. Aysina, A.A. Nesterova, Soc. Psy. and Soc. 10(4), $42-57$ (2019). https://doi.org/10.17759/sps.2019100404

11. I.B. Bovina, N.V. Dvoryanchikov, Psy. Sci. and Edu. 25(3), 101-115 (2020). https://doi.org/10.17759/pse.2020250309

12. A.N. Tatenko, et al., Soc. Psy. and Soc. 11(1), 159-179 (2020). https://doi.org/10.17759/sps.2020110110

13. A.Yu. Popov, A.A. Volochkov, Struktura i psikhologicheskaya diagnostika deyatelnosti studentov [Structure and psychological diagnostics of student activity] (Perm State Humanitarian Pedagogical University, Perm, 2015)

14. A.A. Volochkov (ed.), Aktivnost, tsennostnaya orientatsiya i psikhologicheskoe zdorove studentov [Activity, value orientation and students' psychological health] (Perm State Humanitarian Pedagogical University, Perm, 2015)

15. S.A. Vasyura, Kazan Pedag. J. 2(145), 266-275 (2021). https://doi.org/10.51379/KPJ.2021.146.3.037 